\title{
Fear of falling associated with sociodemographic and lifestyle variables and clinical conditions in elderly people registered with the Family Health Strategy in Campo Grande, Mato Grosso do Sul
}

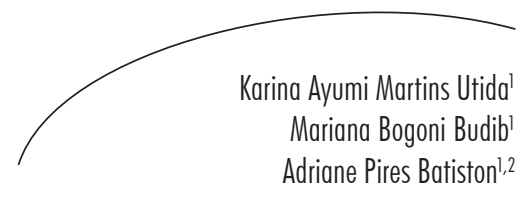

Abstract

Objective: To investigate the prevalence of fear of falling among the elderly and its association with sociodemographic and lifestyle variables, morbidities, balance, mobility and a history of falls (HF). Method: A cross-sectional study was performed in nine family health units in the southern district of Campo Grande, Mato Grosso do Sul. An interview was conducted to obtain data relating to the sociodemographic and clinical variables and the history of falls. The Falls Efficacy Scale-International-Brazil (FES-I-Brazil) and the Timed Up and Go (TUG) test were also applied. Statistical analysis was performed using the Pearson linear correlation test (FES-I-Brazil related to TUG score), the Student's t-test (FES-I-Brazil related to lifestyle, comorbidities and HF) and ANOVA one way, followed by Tukey post-hoc (FES-I-Brazil related to HF and TUG score). Results: Two hundred and one elderly persons with an average age of $70.85( \pm 7.72)$ years were included. On the FES-I-Brazil scale, the overall score was $28.80( \pm 0.82)$ points. The average TUG time was $12.00( \pm 0.57)$ seconds. There was a significant positive linear correlation between the FES-I-Brazil score and the TUG time $(p<0.001)$ and the variables of gender $(p=0.008)$, hypertension ( $p=0.002), \mathrm{FH}(p=0.005)$ and frequency of falls $(p=0.011)$. Conclusion: There is a high frequency of fear of falling among the studied population, as the majority reported fear of falling in at least one of the sixteen FES-I-Brazil tasks. Such fear was significantly associated with hypertension, diabetes mellitus, history of falls, perception of always suffering falls and low scores for mobility and balance.

\footnotetext{
Universidade Federal de Mato Grosso do Sul, Centro de Ciências Biológicas e da Saúde, Curso de Fisioterapia. Campo Grande, Mato Grosso do Sul, Brasil.

2 Universidade Federal de Mato Grosso do Sul, Centro de Ciências Biológicas e da Saúde, Programas de Pós-graduação em Enfermagem e em Saúde da Família. Campo Grande, Mato Grosso do Sul, Brasil.
}

Key words: Health of the Elderly; Accidental Falls; Public Health. 


\section{INTRODUCTION}

The current increase in the elderly population has brought to the fore an important discussion regarding incapacitating events, particularly falls, among this age group. According to the World Health Organization (WHO), a fall is defined as "inadvertently coming to rest on the ground, floor or other lower level, excluding intentional change in position to rest in furniture, wall or other objects."

From 65 years of age onwards, more than a third of people suffer a fall each year, and in half of these cases the accidents are recurrent, ${ }^{2}$ with consequences such as fractures, emotional trauma and reduced mobility, potentially triggering morbidities which can result in a condition of dependence and possible institutionalization for the elderly individuals concerned, ${ }^{3}$ as well as high levels of expenditure on care, making this an important public health issue the world over. ${ }^{4}$

In addition to loss of function caused by physical and psychological trauma, falls can lead to a reduction of both functionality and the performance of activities of daily living due to the fear of repeat incidents. ${ }^{3}$ Earlier studies have found that most people with a fear of falling have the following in common: a history of falls; low scores in functional tests; a greater need for help with the performance of activities of daily living (ADLs); greater perception of fragility in relation to their health; ${ }^{5}$ a less active social life; a limited level of physical activity; a high risk of falling ${ }^{6}$ and a reduced quality of life.?

There is a current trend for elderly people to seek active aging by remaining more socially active, as well as a growing interest on the part of public authorities in developing favorable policies in order to preserve the autonomy and independence of elderly people. ${ }^{4}$

Considering the fact that fear of falling is linked to fragility and to risks of falling, it is important to understand how common this fear and associated factors are among the elderly population. Such knowledge is relevant to managers, health professionals and the elderly individuals themselves, all of whom can take ownership of vulnerable groups and devise strategies to promote active aging in order to prevent falls and their physical, mental and social consequences.

In light of the foregoing, the present study sought to investigate fear of falling among the elderly population and its association with sociodemographic and lifestyle variables, morbidities, balance, mobility and history of falls.

\section{METHOD}

A cross-sectional study was performed which sought to discover the frequency of fear of falling among the elderly and its association with other variables. This is an extremely important component for the functional health of elderly individuals.

Data collection occurred between August 2012 and August 2013. The study was conducted in nine of the ten Unidades Básicas de Saúde da Família - USF (Basic Family Health Units) located in the Southern District of the municipality of Campo Grande in the state of Mato Grosso do Sul. These units were chosen as this southern district is the designated area for research, teaching and extension learning of the Universidade Federal de Mato Grosso do Sul (the Federal University of Mato Grosso do Sul) and is therefore an area of particular interest in terms of the integration of the university with the community through the mediums of investigation and intervention.

The elderly individuals were approached in their homes and informed about the objectives and methodology of the research before being invited to participate in the study, with emphasis given to the fact they were free to refuse and would not be penalized for doing so. The composition of the study sample was based on convenience. Researchers attended USFs on pre-scheduled dates and were informed by community health workers (CHW) as to which of the individuals who had agreed to take part met the conditions 
for doing so. These conditions required the elderly persons to not suffer from difficulties with comprehension and verbal communication or functional limitations that would prevent the performance of the required tests, as well as not use a wheelchair or equipment to aid walking. These criteria were further confirmed by the researcher at the time of each visit.

In terms of data collection, a structured preprepared interview was carried out, with the aim of extracting data regarding sociodemographic and lifestyle factors, health problems and frequency and history of falls (HF) over the past 12 months. The definition of a fall of the WHO was used for evaluating HF. ${ }^{1}$ Next came the application of the Falls Efficacy Scale-International-Brazil (FES-IBrazil), using a version adapted and validated by Camargos et al. ${ }^{8}$ for the Brazilian population based on the Falls Efficacy Scale-International (FES-I) developed by Tinetti et al. ${ }^{5}$ The Brazilian version evaluates fear of falling during the execution of 16 social/external activities, including: cleaning the house; answering the phone; making meals; taking a bath/shower; going shopping; attending church; attending social events; walking on a slippery or bumpy surface and walking up or down ramps. For each activity a score of between 1 and 4 is awarded based on the level of unease expressed by an individual regarding the possibility of suffering a fall: (1) the individual is "not worried" about falling; (2) is "a little worried"; (3) is "moderately worried"; and (4) is "very worried". Total scores can range from 16 to 64 points, with 16 points indicating a lack of concern and 64 points being extremely worried about the possibility of falling whilst carrying out activities.

In order to evaluate mobility and balance, the Timed Up and Go (TUG) test was performed. The test required each individual to sit in a chair with arm rests with their back supported and with the seat and arm rests at a height of approximately $46 \mathrm{~cm}$ and $65 \mathrm{~cm}$ respectively, before being instructed to stand up, walk three meters in a straight line to a point marked on the floor, then turn round and return to sit down with their back resting in the same chair. The subjects are advised not to talk during the test and to perform the task safely at their automatic and habitual speed. The test begins with a starting signal from the evaluator who bends his left arm and gives the verbal command "go" (with the timer starting immediately). The timer is stopped only when the individual is back in their starting position, sitting with their back supported by the chair.

As regards the evaluation of the results, the individuals who were unable to provide all of the information necessary were not included in the inferential statistics. Linear correlation between scores on the FES-I-Brazil scale and the variables of age, body mass index (BMI), years of study and score on the TUG test was performed using the Pearson linear correlation test. With regard to the relationship between scores attained in the FES-I-Brazil test and the following variables: smoking, alcohol consumption, physical activity, hypertension, dyslipidemia and diabetes mellitus, correlation was performed using the Student's t-test. Comparison between patients with different frequencies of falling in relation to FES-I-Brazil scores was performed by means of the ANOVA one-way test, followed by the Tukey post-hoc test. The same test was used to compare the individuals from different score ranges on the FES-I-Brazil scale in relation to the variables of age, BMI, years of study and TUG score. Finally, the chitest square was used to evaluate the association between score ranges in the FES-I-Brazil scale and the variables of gender, smoking, alcohol consumption, physical activity, systemic arterial hypertension ( $\mathrm{SAH}$ ), dyslipidemia, diabetes mellitus and HF. Results related to the other variables evaluated in this study were presented in the form of descriptive statistics or as tables and graphics. Statistical analysis was performed using SPSS software, version 17.0, with 5\% taken as the significance level. ${ }^{9}$

This research project of the study was approved by the Ethics Committee of the Federal University of Mato Grosso do Sul, under protocol no. $1895 / 2010$, and all of the ethical criteria for the study were met, including the signing of the free and informed consent form by all participants. 


\section{RESULTS}

The present study evaluated 201 elderly individuals aged between 60 and 96 years, with a mean age of $70.85( \pm 7.72)$ and a mean BMI of 28.46 $( \pm 0.45) \mathrm{kg} / \mathrm{m}^{2}$. Results for the following variables: gender, ethnicity, marital status, cohabitation, employment and education are detailed in Table 1. In general, most of the individuals were women, with mixed-race and white the most common ethnic groups. Most cohabited and did not work, while the figure for average years of study was $3.25( \pm 0.26)$ years.

Table 1. Distribution of elderly individuals according to sociodemographic variables. Campo Grande, Mato Grosso do Sul, 2013.

\begin{tabular}{lc}
\hline \multicolumn{1}{c}{ Variables } & $\mathrm{n}(\%)$ \\
\hline Gender & $133(66.2)$ \\
Female & $68(33.8)$ \\
Male & \\
Ethnicity & $100(49.8)$ \\
Mixed race & $77(38.3)$ \\
White & $22(10.9)$ \\
Black & $2(1.0)$ \\
No information & \\
Civil status & $109(54.2)$ \\
With partner & $92(45.8)$ \\
Single & \\
Lives with other people & $164(81.6)$ \\
Yes & $37(18.4)$ \\
No & \\
Employed & $173(86.1)$ \\
No & $26(12.9)$ \\
Yes & $2(1.0)$ \\
No information & \\
Literate (among those who never studied n= 65) & $31(47.7)$ \\
No & $26(40.0)$ \\
Yes & $8(12.3)$ \\
No information & \\
\hline
\end{tabular}


Table 2 shows the distribution of the elderly individuals in accordance with the habits of smoking, alcohol consumption and physical activity, as well as $\mathrm{SAH}$, dyslipidemia and diabetes mellitus morbidities and information related to HF.
Most individuals did not smoke or drink alcohol, did not take part in physical activity and suffered from SAH. In general, most individuals had not suffered any falls or resultant hospitalization in the past 12 months, as detailed in table 3 .

Table 2. Distribution of elderly individuals in accordance with lifestyle and morbidities. Campo Grande, Mato Grosso do Sul. 2013.

\begin{tabular}{|c|c|}
\hline Variables & $\mathrm{n}(\%)$ \\
\hline \multicolumn{2}{|l|}{ Smoker } \\
\hline No & $171(85,1)$ \\
\hline Yes & $30(14.9)$ \\
\hline \multicolumn{2}{|l|}{ Alcohol consumption } \\
\hline No & $187(93.0)$ \\
\hline Yes & $14(7.0)$ \\
\hline \multicolumn{2}{|l|}{ Physical activity } \\
\hline No & $158(78.6)$ \\
\hline Yes & $43(21.4)$ \\
\hline \multicolumn{2}{|l|}{ Arterial hypertension } \\
\hline No & $50(24.9)$ \\
\hline Yes & $151(75.1)$ \\
\hline \multicolumn{2}{|l|}{ Cardiac } \\
\hline No & 164 (81.6) \\
\hline Yes & 37 (18.4) \\
\hline \multicolumn{2}{|l|}{ Dyslipidemia } \\
\hline No & $141(70.1)$ \\
\hline Yes & $59(29.4)$ \\
\hline No information & $1(0.5)$ \\
\hline \multicolumn{2}{|l|}{ Diabetes mellitus } \\
\hline No & $136(67.7)$ \\
\hline Yes & $65(32.3)$ \\
\hline
\end{tabular}


Table 3. Distribution of elderly individuals in accordance with history and frequency of falls and related hospital admissions. Campo Grande, Mato Grosso do Sul, 2013.

\begin{tabular}{lc}
\hline \multicolumn{1}{c}{ Variables } & $\mathrm{n}(\%)$ \\
\hline History of falls & $146(72.6)$ \\
No & $53(26.4)$ \\
Yes & $2(1.0)$ \\
No information & \\
Frequency of falls & $111(55.2)$ \\
Never & $75(37.3)$ \\
Sometimes & $10(5.0)$ \\
Yes & $5(2.5)$ \\
No information & \\
Hospitalization for falls in the last 12 months & $179(89.1)$ \\
No & $18(9.0)$ \\
Yes & $4(2.0)$ \\
No information &
\end{tabular}

Most of the elderly respondents did not have private health insurance $(65.2 \%)$ while the vast majority $(96.0 \%)$ reported being visited by professionals from the family health team, of whom all $(100.0 \%)$ were visited by a CHW. Only 36 $(18.6 \%)$ of the individuals reported receiving visits from doctors and/or nurses, with only seven (3.6\%) having been visited by a social worker and just two $(1.0 \%)$, by a dentist. Among men $(\mathrm{n}=68)$, most had undergone a prostate examination $(77.9 \%)$, and among women $(\mathrm{n}=133)$ most had undergone a clinical breast exam (71.4\%) and a Pap smear test $(69.2 \%)$.

The FES-I-Brazil scale score was $28.80( \pm 0.82)$ points, with $39.8 \%$ of elderly individuals showing little concern about falling, 23.4\% moderately worried and $34.3 \%$ extremely worried. In the TUG test, the average time registered was 12.00 $( \pm 0.57)$ seconds, equivalent to the level expected for disabled or fragile elderly persons with partial independence and a low risk of falling.

There was no linear correlation between FESI-Brazil scale scores and variables of age (Pearson linear correlation test, $\left.\mathrm{p}=0.455 ; \mathrm{r}=0.054, \mathrm{r}^{2}=0.003\right)$, BMI ( $\left.\mathrm{p}=0.409 ; \mathrm{r}=0.059, \mathrm{r}^{2}=0.004\right)$ or education $\left(\mathrm{p}=0.754 ; \mathrm{r}=0.023, \mathrm{r}^{2}=0.001\right)$. However, there was a significant positive linear correlation between scores on the FES I-Brazil scale and TUG test times, as shown in Figure 1 ( $p<0.001 ; r=0.296$; $\left.\mathrm{r}^{2}=0.087\right)$. 


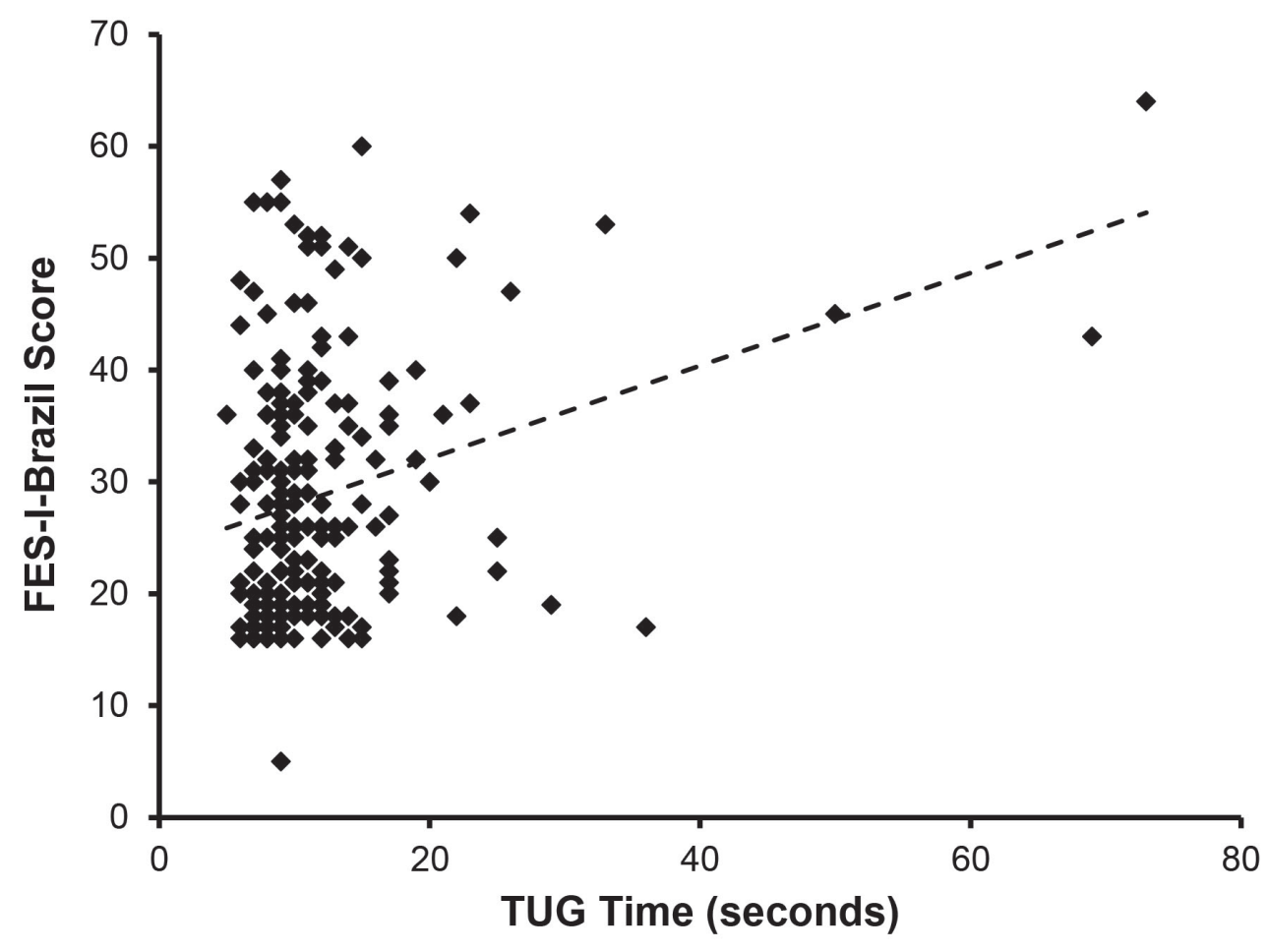

Each symbol represents a score on the FES-I-Brazil scale and a time on the TUG test for one elderly individual. The dotted line represents the linear regression line.

Figure 1. Dispersion graph of linear correlation between FES-I-Brazil scores and TUG test times among the elderly individuals evaluated. Campo Grande, Mato Grosso do Sul, 2013.

No difference was noted among the individuals with different FES-I-Brazil scale score ranges in terms of age, BMI or years of study (ANOVA one-way, $p$ value ranging between 0.149 and 0.684 ). On the other hand, the TUG test results among the individuals with FES-I-Brazil scores between 32-64 points were significantly higher than for individuals with scores ranging between 16 and 22 points and between 23 and 31 points (ANOVA one-way, $\mathrm{p}=0.006$; Tukey post-hoc, $\mathrm{p}<0.05)$.
Table 4 shows the distribution of individuals according to their FES-I-Brazil score range in relation to gender, lifestyle, morbidities and HF. There was no significant association between FESI-Brazil score range and the variables of smoking, physical activity, dyslipidemia and diabetes mellitus (chi-square test, $\mathrm{p}$ value ranging between 0.058 and 0.840). On the other hand, there was a significant association between FES-I-Brazil score range and variables of gender $(p=0.008), \mathrm{SAH}(\mathrm{p}=0.002)$, $\mathrm{HF}(\mathrm{p}=0.005)$ and frequency of falls $(\mathrm{p}=0.011)$. 
Table 4. Distribution of elderly individuals in accordance with score range on the FES-I-Brazil scale and the variables of gender, lifestyle, morbidities and history of falls. Campo Grande, Mato Grosso do Sul, 2013.

\begin{tabular}{|c|c|c|c|c|}
\hline \multirow{2}{*}{ Variables } & \multicolumn{3}{|c|}{ Score on the FES-I-Brazil scale - $\mathrm{n}(\%)$} & \multirow{2}{*}{ Value of $p$} \\
\hline & 16 to 22 points & 23 to 31 points & 32 to 64 points & \\
\hline \multicolumn{5}{|l|}{ Gender* } \\
\hline Female & $43(33.1)$ & $36(27.7)$ & $51(39.2)$ & \multirow{2}{*}{0.008} \\
\hline Male & $37(56.1)$ & $11(16.7)$ & $18(27.3)$ & \\
\hline \multicolumn{5}{|l|}{ Smoker* } \\
\hline No & $69(41.3)$ & $42(25.1)$ & $56(33.5)$ & \multirow{2}{*}{0.447} \\
\hline Yes & $11(37.9)$ & $5(17.2)$ & $13(44.8)$ & \\
\hline \multicolumn{5}{|c|}{ Alcohol consumption* } \\
\hline No & $73(40.1)$ & $45(24.7)$ & $64(35.2)$ & \multirow{2}{*}{0.637} \\
\hline Yes & $7(50.0)$ & $2(14.3)$ & $5(35.7)$ & \\
\hline \multicolumn{5}{|c|}{ Physical activity* } \\
\hline No & $64(41.0)$ & $34(21.8)$ & $58(37.2)$ & \multirow{2}{*}{0.305} \\
\hline Yes & $16(40.0)$ & $13(32.5)$ & $11(27.5)$ & \\
\hline \multicolumn{5}{|c|}{ Arterial hypertension* } \\
\hline No & $28(58.3)$ & $13(27.1)$ & 7 (14.6) & \multirow{2}{*}{0.002} \\
\hline Yes & $52(35.1)$ & $34(23.0)$ & $62(41.9)$ & \\
\hline \multicolumn{5}{|c|}{ Dyslipidemia ** } \\
\hline No & $58(42.3)$ & $28(20.4)$ & $51(37.2)$ & \multirow{2}{*}{0.276} \\
\hline Yes & $22(37.9)$ & $18(31.0)$ & $18(31.0)$ & \\
\hline \multicolumn{5}{|c|}{ Diabetes mellitus* } \\
\hline No & $59(44.7)$ & $34(25.8)$ & $39(29.5)$ & \multirow{2}{*}{0.058} \\
\hline Yes & $21(32.8)$ & $13(20.3)$ & $30(46.9)$ & \\
\hline \multicolumn{5}{|c|}{ Fallen in the past 12 months*** } \\
\hline No & $65(46.1)$ & $35(24.8)$ & $41(29.1)$ & \multirow{2}{*}{0.005} \\
\hline Yes & $13(24.5)$ & $12(22.6)$ & $28(52.8)$ & \\
\hline \multicolumn{5}{|c|}{ Frequency of falls $* * * *$} \\
\hline Never & $54(50.0)$ & $21(19.4)$ & $33(30.6)$ & \multirow{3}{*}{0.011} \\
\hline Sometimes & $23(31.1)$ & $23(31.1)$ & $28(37.8)$ & \\
\hline Always & $1(10.0)$ & $2(20.0)$ & $7(70.0)$ & \\
\hline \multicolumn{5}{|c|}{$\begin{array}{l}\text { Hospitalization for fall } \\
\text { in the past } 12 \text { months**** }\end{array}$} \\
\hline No & $74(42.3)$ & $44(25.1)$ & 57 (32.6) & \multirow{2}{*}{0.240} \\
\hline Yes & $5(29.4)$ & $3(17.6)$ & $9(52.9)$ & \\
\hline
\end{tabular}

* Information not available for five individuals; ${ }^{* *}$ Information not available for six individuals; $* * *$ Information not available for seven individuals; ${ }^{* * *}$ Information not available for nine individuals. 


\section{DISCUSSION}

Findings from current literature show important differences in the frequency of fear of falling amongst elderly populations, ranging from $24 \%$ to $92.5 \% \cdot{ }^{10-14}$ Studies of older people living in developed countries found that frequency ranged between $24 \%$ and $43 \%,{ }^{10,11,13}$. Where the population assessed was elderly Brazilians, however, this number has always been high (59.7 to $92.5 \%),{ }^{12,14,15}$ as it was in this study, where fear of falling was an issue for almost all the individuals encountered. This difference possibly arises from the fact that appropriate physical environments lead to greater independence for the elderly, whereas when barriers in the physical environment are encountered elderly individuals tend to leave home less and are more inclined to isolation, depression, reduced fitness, and more problems with mobility with a consequent increase in the fear of falling. ${ }^{16}$

The results showed that HF is not a necessary component for fear of falling, as fewer than a third of individuals who reported fear had a HF. The chance of this fear being present, however, increases among those with $\mathrm{HF},{ }^{17,18}$ since all the individuals with HF encountered in this study showed a fear of falling in at least one task proposed by the FES-I-Brazil. A study by Lopes et al., ${ }^{17}$ who evaluated 111 elderly individuals, showed similar results, with $54.42 \%$ of individuals having HF and $96.25 \%$ of these reporting a fear of falling. Another study showed that among elderly individuals who had already suffered falls, $84.16 \%$ had a fear of falling; while among those with no history of falls the figure was just $63.16 \%{ }^{18-}$

Another finding from the present study was that women presented higher scores for fear of falling compared to men, corroborating the results of several other studies. ${ }^{19-22}$ Authors have suggested that lower levels of fear of falling for males may be related to the fact that men do not tend to admit to this fear, with the quantification of fear of falling using the FES-I-Brazil scale dependent on honest responses by individuals to a series of questions. ${ }^{23-25}$ Moreover, Fletcher \& Hirdes $^{26}$ believe that women overestimate the risk and consequences of falls whereas men underestimate them. Another factor that could justify the higher levels of fear amongst women is that they suffer more than men from a decline in the muscular system and in functionality compared to men. ${ }^{26-29}$

The study also showed that worry about falling was greater among individuals with hypertension and diabetes mellitus, as was also the case in the study by Antes et al. ${ }^{21}$ However it was not possible to establish a correlation between these diseases and frequency of fear of falling.

Fear of falling is strongly associated not only with decreased balance, but also with reductions in mobility, physical activity, ${ }^{30}$ socialization and independence as well as with increases in morbidity, mortality and number of falls. ${ }^{30}$ This suggests a vicious circle, in which the risk of falling leads to reductions in balance and mobility and to fear of falling and functional decline, all of which result in more fear. ${ }^{31}$ On the other hand, physical activity positively influences muscle strength and balance, helping reduce the level of fear in order to break this cycle. ${ }^{32}$ This study found no significant correlation between fear of falling and physical activity. In contrast, one aspect that stands out is the high rate of sedentary elderly individuals $(78.6 \%)$, which is significant given the knowledge that physical activity contributes to healthier aging, with higher fitness levels being related to a lower risk of morbidity and mortality and to the prevention of falls. ${ }^{1}$ Physical activity has the additional benefit of being a low-cost pursuit.

Regarding the FES-I-Brazil scale, the findings of this study were similar to the study by Rodrigues et al., ${ }^{33}$ which indicated an average of 31 points, although the scores were higher than those of a validation study of the same scale in Brazil, where the average score was $23.55 .{ }^{8}$ In two further Brazilian studies, ${ }^{17,34}$ the average score on the FESI-Brazil scale was 24.01 and 26.5, respectively. There were no factors identified which could have possibly influenced the difference in levels of fear of falling of the elderly persons included in this study as compared to those investigated in the other research. ${ }^{8,17,34}$ 
As regards the TUG test, the average result returned corresponds to a level expected from disabled or fragile elderly individuals, with partial independence and a low risk of falling. This reflects the results of a case control study by Pimentel \& Scheicher ${ }^{14}$ which evaluated the TUG times of a group with HF and another group without HF, with the former group returning an average time of 11.6 seconds and the latter 11.49. A study by Lopes et al. ${ }^{17}$ found an average time of $17.73( \pm 7.78)$ seconds, which also corresponds to the timeframe expected for disabled or fragile elderly persons with partial independence and a lower risk of falling. To maintain balance while walking, elderly individuals act with caution, creating strategies to reduce the risk of falls. For example, reducing the time spent in the swing phase, which is the phase of greatest instability, and decreasing momentum, knee extension and the length and height of step, consequently reducing the speed of walking. In fact, however, a normal level of speed allows for greater stability. ${ }^{35}$

A significant relationship was encountered $(p=0.006)$, when comparing the score range of individuals on the FES-I-Brazil scale in relation to their TUG results, indicating that less mobile individuals are more afraid of falling, which indicates that this fear may be based on lower functional ability and balance. However, it is known that the fear of falling leads to functional decline, ${ }^{32}$ so it is not possible to determine whether fear of falling has led to restriction of mobility or vice versa.

We are currently witnessing a rapid transition in global demographics and epidemiology, with an observable disharmony between the speed of this transition and the inception of actions aimed at improvements in primary health care and health promotion. In these circumstances, the importance of everyday physical activity in order to combat physical decline and consequently improve quality of life should not be underestimated. Nowadays, many USFs develop walking and exercise programs for the elderly, but in many cases there are difficulties in ensuring the adherence of targeted individuals, thus explaining the need for changes or improvements in the strategies aimed at this population.

This study was the first of its kind to be carried out with the elderly population of Campo Grande, Mato Grosso do Sul, and as such it is important with regards to future research in this area. In addition, only a few studies ${ }^{14,15,17}$ were found in Brazilian literature which correlated fear of falling as measured on the FES-I-Brazil scale with mobility and balance measured using the TUG test.

In terms of the limitations of this study, it should be mentioned that the sample used was for purposes of convenience, chosen with the assistance of CHWs. However, these professionals have strong links and regular contact with the elderly population treated at the USFs. In addition, no prior survey was performed in order to discover the number of physically active elderly individuals registered at each USF, making it impossible to create a proportional sample. Finally, as this was a cross-sectional study it was not possible to prove any temporal correlation or relationship of cause and effect.

\section{CONCLUSION}

In conclusion, there was a highly significant fear of falling among the population studied, with the vast majority of individuals reporting such a fear in at least one of the 16 tasks of the FES-IBrazil scale. This fear was shown to be strongly associated with the variables of systemic arterial hypertension, diabetes mellitus, history of falls, the perception of individuals that they always fall and low scores for mobility and balance. 


\section{REFERENCES}

1. World Health Organization. Global report on falls prevention in older age [Internet]. Genebra: WHO; 2007 [acesso em 17 nov. 2015]. Disponível em: http://www.who.int/ageing/publications/Falls_ prevention7March.pdf?ua=1

2. Gillespie LD, Robertson MC, Gillespie WJ, Sherrington C, Gates S, Clemson LM, et al. Interventions for preventing falls in older people living in the community. Cochrane Database Syst Rev 2012;9:1-5.

3. Gallardo MA, Asencio MMJ, Sanchez JCC, Sojo BS, Perez JC, Fernandez AM, et al. Instruments for assessing the risk of falls in acute hospitalized patients: a systematic review and meta-analysis. BMC Health Serv Res 2013;13:122.

4. Veras R. Envelhecimento populacional contemporâneo: demandas, desafios e inovações. Rev Saúde Pública 2009;43(3):548-54.

5. Tinetti ME, Richman D, Powell L. Falls efficacy as a measure of fear of falling. J Gerontol 1990;45(6):239-43.

6. Park JH, Cho H, Shin JH, Kim T, Park SB, Choi $\mathrm{BY}$, et al. Relationship among fear of falling, physical performance, and physical characteristics of the rural elderly. Am J Phys Med Rehabilit 2014;93(5):379-86

7. Hartholt KA, Van Beeck EF, Polinder S, Van der Velde N, Van Lieshout EM, Panneman MJ, et al. Consequences of falls in the older population: Injuries, healthcare costs, and long-Term reduced quality of life. J Trauma 2011;71(3):748-53

8. Camargos FFO, Dias RC, Dias JMD, Freire MTF. Adaptação transcultural e avaliação das propriedades psicométricas da Falls Efficacy Scale - International em idosos brasileiros (FES-I-BRASIL). Rev Bras Fisioter 2010;14(3):237-43.

9. Shott S. Statistics for health professionals. London: W.B. Saunders Company; 1990.

10. Lach HW. Incidence and risk factors for developing fear of falling in older adults. Public Health Nurs 2005;22(1):45-52.

11. Murphy SL, Williams CS, Gill TM. Characteristics associated with fear of falling and activity restriction in community-living older persons. J Am Geriatr Soc 2002;50(3):516-20.

12. Ricci NA, Gonçalves DFF, Coimbra IBC. Fatores associados ao histórico de quedas de idosos assistidos pelo Programa de Saúde da Família. Saúde Soc 2010;19(4):898-909.
13. Tinetti ME, De Leon CFM, Doucette JT, Baker DI .Fear of falling and fall-related efficacy in relationship to functioning among community-living elders. J Gerontol 1994;49(3):140-7.

14. Pimentel I, Scheicher ME. Comparação da mobilidade, força muscular e medo de cair em idosas caidoras e não caidoras. Rev Bras Geriatr Gerontol 2013;16(2);251-57.

15. Silva A, Faleiros HH, Shimizu WAL, Nogueira LM, Nhãn LL, Silva MF, et al. Prevalência de quedas e de fatores associados em idosos segundo etnia. Ciênc Saúde Coletiva 2012;17(8):2181-90.

16. World Health Organization. Envelhecimento ativo: uma política de saúde. Suzana Gontijo, tradutor. Brasília, DF: Organização Pan-Americana da Saúde; 2005.

17. Lopes KT, Costa DF, Santos LF, Castro DP, Bastone AC. Prevalência do medo de cair em uma população de idosos da comunidade e sua correlação com mobilidade, equilíbrio dinâmico, risco e histórico de quedas. Rev Bras Fisioter 2009;13(3):223-9.

18. Fernandes MGM, De Oliveira FMRL, Barbosa KTF. Avaliação do medo de cair em idosos em atendimento ambulatorial. Rev Enferm UFPE on line 2013; 7(4):1160-6.

19. Delbaere K, Crombez G, Vanderstraeten G, Willems T, Cambier D. Fear-related avoidance of activities, falls and physical frailty: a prospective communitybased cohort study. Age Ageing 2004;33(4):368-73

20. Kempen GI, Van Haastregt JC, McKee KJ, Delbaere $\mathrm{K}$, Zijlstra GA. Socio-demographic, health-related and psychosocial correlates of fear of falling and avoidance of activity in community-living older persons who avoid activity due to fear of falling. BMC Public Health 2009 2;9:1-14.

21. Antes DL, Schneider IJC, Benedetti TR, D'orsi E. Medo de queda recorrente e fatores associados em idosos de Florianópolis, Santa Catarina, Brasil. Cad Saúde Pública 2013;29(4):758-68.

22. Legters K. Fear of falling. Phys Ther 2002;82(3):264-72.

23. Tinetti ME, Williams CS. The effect of falls and falls and fall infuries on functioning in communitydwelling older persons. J Gerontol 1998;53(2):112-9.

24. McAuley E, Mihalko SL, Rosengren K. Self-efficacy and balance correlates of fear of falling in the elderly. J Aging Phys Act 1997;5:329-340. 
25. Malini FM, Lopes CS, Lourenço RA. Medo de quedas em idosos: uma revisão da literatura. Rev HUPE 2014;13(2):38-44.

26. Fletcher PC, Hirdes JP. Restriction in activity associated with fear of falling among communitybased seniors using home care services. Age Ageing 2004;33:273-9.

27. Myers AM, Powell LE, Maki BE, Holliday PJ, Brawley LR, Sherk W. Psychological indicators of balance confidence: relationship to actual perceived abilities. J Gerontol 1996;51:37-43.

28. Lachman ME, Howland J, Tennstedt S, Jette A, Assmann S, Peterson EW. Fear of falling and activity restriction: the survey of activities and fear of falling in the elderly (SAFE). J Gerontol Ser B Psychol Sci Soc Sci 1998;53(1):43-50

29. Martin FC, Hart D, Spector T, Doyle DV, Harari D. Fear of falling limiting activity in young-old women is associated with reduced functional mobility rather than psychological factors. Age Ageing 2005;34(3):281-7.

30. Suzuki M, Ohyama N, Yamada K, Kanamori M. The relationship between fear of falling, activities of daily living and quality of life among elderly individuals. Nurs Health Sci 2002;4:155-61.
31. Gillespie SM, Friedman SM. Fear of falling in new long-term care enrollees. J Am Med Dir Assoc 2007;8(5):307-13.

32. Mazo GZ, Liposcki DB, Ananda C, Prevê D. Condições de saúde, incidência de quedas e nível de atividade física dos idosos. Rev Bras Fisioter 2007;11(6):437-42.

33. Rodrigues IG, Costa GA, Pinto RMC. Qualidade de vida e senso de auto-eficácia para quedas em idosos participantes do Projeto AFRID/UFU. Efdesportes. com [Internet] 2009 [acesso 20 nov.2013];13(129):1-6. Disponível em: http://www.efdeportes.com/efd129/ qualidade-de-vida-e-senso-de-auto-eficacia-paraquedas-em-idosos.htm

34. Silva SLA, Vieira RA, Arantes P, Dias RC. Avaliação de fragilidade, funcionalidade e medo de cair em idosos atendidos em um serviço ambulatorial de geriatria e gerontologia. Fisioter Pesqui 2009;16(2):120-5.

35. Moreira MA, Oliveira BS, Moura KQ, Tapajós DM, Maciel ACC. A velocidade da marcha pode identificar idosos com medo de cair?. Rev Bras Geriatr Gerontol 2013;16(1):71-80. 